\title{
The Facial Width-to-Height Ratio (fWHR) and Perceived Dominance and Trustworthiness: Moderating Role of Social Identity Cues (Gender and Race) and Ecological Factor (Pathogen Prevalence)
}

\author{
(PSA001 Secondary Analysis) \\ Subramanya Prasad Chandrashekar \\ Open University of Hong Kong
}

\author{
Corresponding Author \\ Subramanya Prasad Chandrashekar \\ 30 Good Shepherd St, Ho Man Tin, \\ Kowloon, Hong Kong \\ Email: spchandr@ouhk.edu.hk
}

\begin{abstract}
People effortlessly form trait impressions from faces, and these impressions can affect a variety of important social and economic outcomes. Trait impressions based on facial features can be approximated to distinct dimensions: trustworthiness and dominance (Oosterhof \& Todorov, 2008). One of the facial features, the facial width-to-height ratio (face ratio) is associated with the trait impressions. I tested whether social category (gender, race) of the target being perceived shapes the relationship between face ratio and perception of dominance and trustworthiness. In this preregistered study, using trait impression ratings of faces collected from 8800 participants across 44 countries, I employ mixed-effects analysis and report results on (1) the direct influence of social categories (gender and race) of the target on perceived dominance and trustworthiness, (2) the moderating role of social categories (gender and race) on the direct relationships between face ratio and perceived dominance and trustworthiness, and (3) the moderating role of pathogen prevalence on the direct relationships between face ratio and perceived dominance and trustworthiness.
\end{abstract}

Keywords: face perception, social perception, facial width-to-height ratio, dominance, trustworthiness 


\section{Introduction}

In the majority of social interactions, people form first impressions of others solely based on facial appearance (Oosterhof \& Todorov, 2008), and these impressions are often subconsciously registered in the minds (Willis \& Todorov, 2006). More importantly, the impression formed based on the facial cues influences social and economic consequences, ranging from punishment-related decisions in court to hiring decisions (Gomulya, Wong, Ormiston, \& Boeker, 2017; Rezlescu, Duchaine, Olivola, \& Chater, 2012; Wilson \& Rule, 2015). The cognitive processes involved in the formation of trait impressions based on facial cues are quick and do not require deliberate cognitive effort (Willis \& Todorov, 2006), enabling perceivers to make interpersonal decisions effortlessly.

The research on first impression formation based on facial cues is grounded in the theories that relate interconnections between various traits to a small number of dimensions that explain the structure of impressions (Fiske, Cuddy, Glick, \& Xu, 2002; Rosenberg, Nelson, \& Vivekananthan, 1968). Work by Oosterhof and Todorov (2008) has shown that spontaneous face-based person impressions can be approximated by two dimensions: trustworthiness and dominance. However, the structure of inferences may vary due to facial features, gender, and race (Oh, Buck, \& Todorov, 2019; Oh, Dotsch, Porter, \& Todorov, 2020). How first impressions based on facial cues are affected by social categories and other factors is still poorly understood.

\section{The effect of facial width-to-height ratio (fWHR) on the perception of trustworthiness and}

\section{dominance}

Researchers have examined the facial width-to-height ratio (fWHR) as a crucial facial feature which implicitly influences perceivers' impression of others. A recent meta-analysis by Geniole and colleagues (2015) found that individuals with larger fWHR were judged as more threatening and dominant. This finding suggests that perceivers tend to perceive a higher fWHR as a signal of dominance and untrustworthiness (Haselhuhn, Wong, \& Ormiston, 2013; Stirrat \& Perrett, 2010). This aspect of trait impression formation has been studied in narrower contexts, such as in a dating scenario (Valentine, Li, Penke, \& Perrett, 2014), mate preferences (Oh, Grant-Villegas, \& Todorov, 2019), and intergroup competition (Hehman, Leitner, Deegan, \& Gaertner, 2015). These studies disproportionally document ratings of perceived dominance based on men's facial features (Lieberz et al., 2017). 
The understanding that we currently have of the effects of face ratio on impressions derives from studies conducted in narrow settings; second, how the attributed traits based on the face ratio differ with social categories (gender, race) is underexplored. Therefore, in the current preregistered study, I set out to test the generalizability of the relationship between face ratio and perceived trustworthiness and dominance based on large cross-country face-image ratings collected from over 8,500 participants in 44 countries (Jones et al., 2018). I hypothesize that the face ratio correlates positively with the dominance dimension measure, and correlates negatively with the trustworthiness dimension measure.

\section{The moderating role of gender and race}

In previous studies, the perceptions of dominance and trustworthiness have typically been investigated for male faces (e.g., Boshyan, Zebrowitz, Franklin, McCormick, \& Carré, 2014; Carré, McCormick, \& Mondloch, 2009; Carré, Morrissey, Mondloch, \& McCormick, 2010; Geniole, Keyes, Mondloch, Carré, \& McCormick, 2012; Geniole, Molnar, Carré, \& McCormick, 2014; Lefevre \& Lewis, 2014; Short et al., 2012). Beyond face impression research, a rich body of work in social psychology has shown the importance of social categories such as gender and race in forming quick judgments and expectations of behaviors (Allport, 1954; Fiske, 2012). Recent work suggests meaningful variations in the formation of the impressions from facial appearance when the target face is male vs. female (Oh et al., 2019; Oh et al., 2020; Sutherland, Young, Mootz, \& Oldmeadow, 2015). Therefore, I investigate how facial features, along with the social categories like gender and race, influence the trait inferences.

Mileva et al. (2014) found in an empirical study that the face ratio was positively associated with the dominance dimension, but only in men. Here, I predict that the positive relationship between face ratio and dominance dimension is stronger when the target faces rated are men (vs. women), and white (vs. other races such as Asian, Black, Latino). Furthermore, I tested for the prediction that the gender of the target will moderate the negative relationship between the face ratio and perceived trustworthiness, such that the relationship is stronger for women than men.

\section{The moderating role of pathogen prevalence}

Research work on mate preference taking an evolutionary view shows that judgments on mate preferences based on facial features are influenced by environmental factors such as 
pathogen prevalence (DeBruine, Jones, Crawford, Welling, \& Little, 2010; Little, DeBruine, \& Jones, 2011). As facial masculinity is associated with genetic quality in both men and women (Thornhill \& Gangestad, 2006), women in countries with high pathogen prevalence prefer more masculine faces than women living in countries with lower pathogen loads (DeBruine, Little, \& Jones, 2012). Although much of this research has focused on explaining peoples' partner preferences based on facial features, the structure of trait impressions may vary meaningfully across countries due to variations in pathogen prevalence. In the current preregistered study, I examine this possibility as an exploratory analysis.

\section{Methods}

All materials, including the preregistered analysis R script and fWHR measures, are available at https://osf.io/5b2c7.

Participants and Procedure. The data was collected for the Psychological Science Accelerator-001 project (PSA-001). The PSA-001 is a multi-country collaboration project testing the replicability and generalizability of the findings by Oosterhof and Todorov (2008). The data was collected across 48 countries, and more than 11,000 participants took part in the study. Participants rated 120 faces (120 images consisted of 30 Black (15 male, 15 female), 30 White (15 male, 15 female), 30 Asian (15 male, 15 female), and 30 Latin faces (15 male, 15 female)). The pictures of the faces were drawn from Chicago Face Database (Ma, Correll, \& Wittenbrink, 2015) and were presented in a randomized order to the participants on a computer screen. Participants rate 120 images on one of the randomly assigned trait dimension of 13 trait dimensions (i.e., aggressive, attractive, caring, confident, dominant, emotionally stable, intelligent, mean, responsible, sociable, trustworthy, unhappy, weird). See Jones et al. (2018) for more details.

\section{Measures.}

Dominance and trustworthiness perceptions. Based on the valence-dominance model (Oosterhof \& Todorov, 2008), I classify trait ratings into two broad dimensions: 1) trustworthiness (trustworthy, emotionally stable, intelligent, responsible, sociable, caring, attractive), and 2) dominance (aggressive, dominant, mean). I did not include "confident" and "weird," in the current analysis as these two items cross-loaded on both trustworthiness and dominance dimension (Jones et al., 2018). Furthermore, although "unhappy" aligned with the trustworthiness dimension, it would have required us to reverse code the item to be included 
along with other items in the trustworthiness dimension, and that could change the face validity of the item. The adjectives were rated on a scale ranging from 1 (Not at all) to 9 (Very).

The pathogen prevalence. The country-level pathogen score was based on Murray and Schaller's (2010) work that document numerical estimates of the historical incidence of pathogens in 230 geopolitical regions worldwide. The authors proposed two scores: 9-item scores, and 7-item scores. In the current analysis, I employ the 7-item score as it offered a wider coverage with PSA-001 data.

Face ratio or Facial Width-to-Height Ratio (FWHR). Participants rated faces drawn from the publicly available Chicago Face Database intended for use in scientific research (CFD; Ma, Correll, \& Wittenbrink, 2015). The values of face ratio were downloaded from the online portal for CFD.

\section{Data analysis}

The predictions were tested using the lme4 package in R (Bates, Mächler, Bolker, \& Walker, 2015). The testing of each prediction involved two mixed-effect models by fitting the regressions with and without the prediction terms. To determine the significance of the predicted effects, I employed a nested model comparison using the Chi-square test in $\mathrm{R}$ (anova function) to compare the full model with the corresponding model lacking the predictor of interest. To interpret the interaction effects, I plotted the interactions and conducted contrasts using the emmeans function from the emmeans package in R.

\section{Results}

\section{Dataset summary and descriptive statistics}

The responses from 8,851 ( $M_{\text {age }}=22.61, S D=6.94 ; 6167$ females) participants were included in the current analysis. The distribution of ratings on the dominance and trustworthiness dimensions is reported in Figure 1. The mean rating for the dominance dimension was $4.2(\mathrm{SD}=1.82)$ and for trustworthiness, it was $5.02(\mathrm{SD}=1.82)$. 

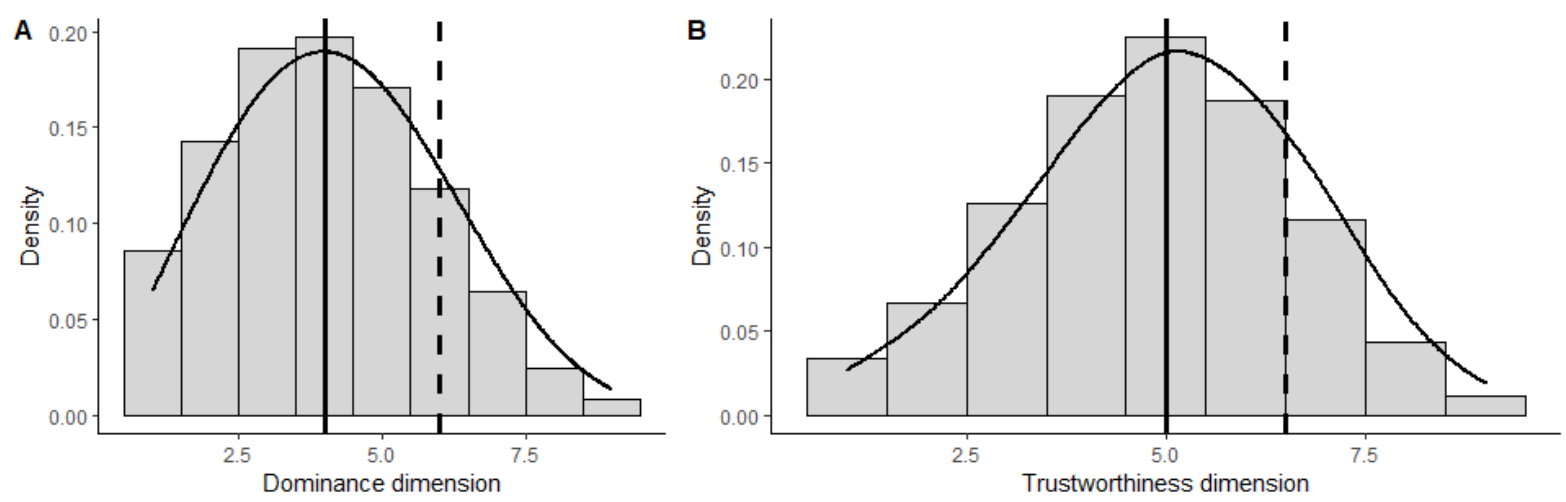

Figure 1. Distribution of ratings of the outcome variables. (A) Distribution for perceived dominance dimension. mode $=3.99$, 80th percentile $=6$. (B) Distribution for perceived trustworthiness dimension. mode $=4.99,80$ th percentile $=6.5$.

\section{Influence of face ratio on perceived dominance and trustworthiness dimension}

Two sets of mixed-effects regression analyses were performed using the lme 4 package in $\mathrm{R}$ (Bates et al., 2015) to assess the effect of face ratio on the dominance and trustworthiness dimensions. In each analysis, I included fixed effects of all factors (gender, age, race, fWHR score), as well as the country of the participant as the random intercept. The results did not find support for a positive association between face ratio of the target in the photographs and perceived dominance (estimate $\left.=0.03 \pm 0.02(\mathrm{SE}), \chi^{2}=1.87, p=.17\right)$. In contrast, results provide support for the negative association between face ratio and perceived trustworthiness (estimate $\left.=-0.83 \pm 0.01(\mathrm{SE}), \chi^{2}=3879.04, p<.001\right)$. I then set out to analyze the interaction effects.

The moderating role of gender and race between face ratio on perceived dominance and trustworthiness dimension

I independently examined whether the effects of face ratio on perceived dominance and on perceived trustworthiness were moderated by gender of the target. To test this, I built mixedeffects models which, in addition to direct effects of predictors, included all 2-way interactions with study context (fWHR*gender, fWHR*age, fWHR*race) as fixed effects separately predicting perceived dominance and perceived trustworthiness. I found, in both cases, interaction results were significant. The interaction results (Fig. 2A) indicate that the strength of the positive relationship between face ratio and perceived dominance was greater for men than women (estimate $=0.58 \pm 0.05(\mathrm{SE}), \chi^{2}=157.42, p<.0001$ ). Furthermore, the strength of the negative relationship (Fig. 2B) between face ratio and perceived 
trustworthiness is stronger for women than men (estimate $=-1.26 \pm 0.05(\mathrm{SE}), \chi^{2}=1941.88$, $p<.001)$.
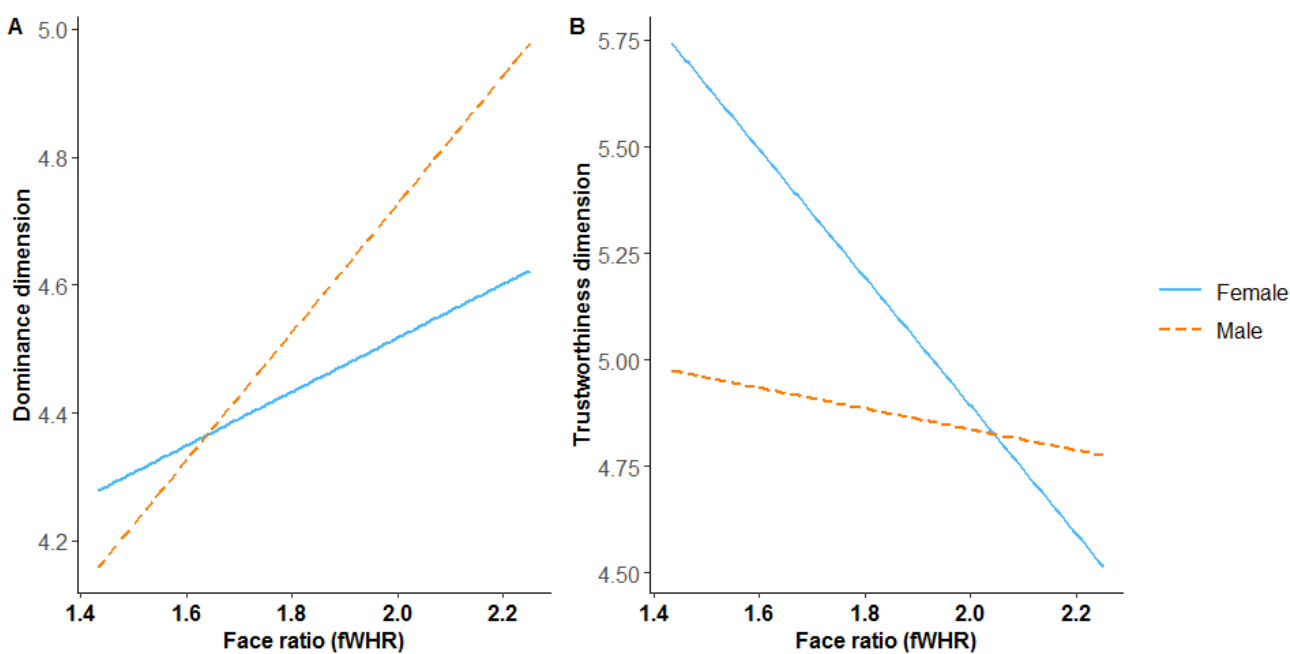

Figure 2. Moderation effects of the target's gender. A) Gender-by-fWHR on perceived dominance. B). Gender-by-fWHR on perceived trustworthiness.

In the same vein, I looked for the moderation effect of race. The results provide support for the prediction that the positive relationship between face ratio and perceived dominance is stronger when the target is a white person (Fig. 3A) than a person belonging to a non-white racial category $\left(\chi^{2}(2)=158.35, p<0.0004\right)$. In predicting the perceived trustworthiness, I found significant interactions between face ratio and race $\left(\chi^{2}(2)=2493.75, p<0.001\right.$; Fig. 3B).
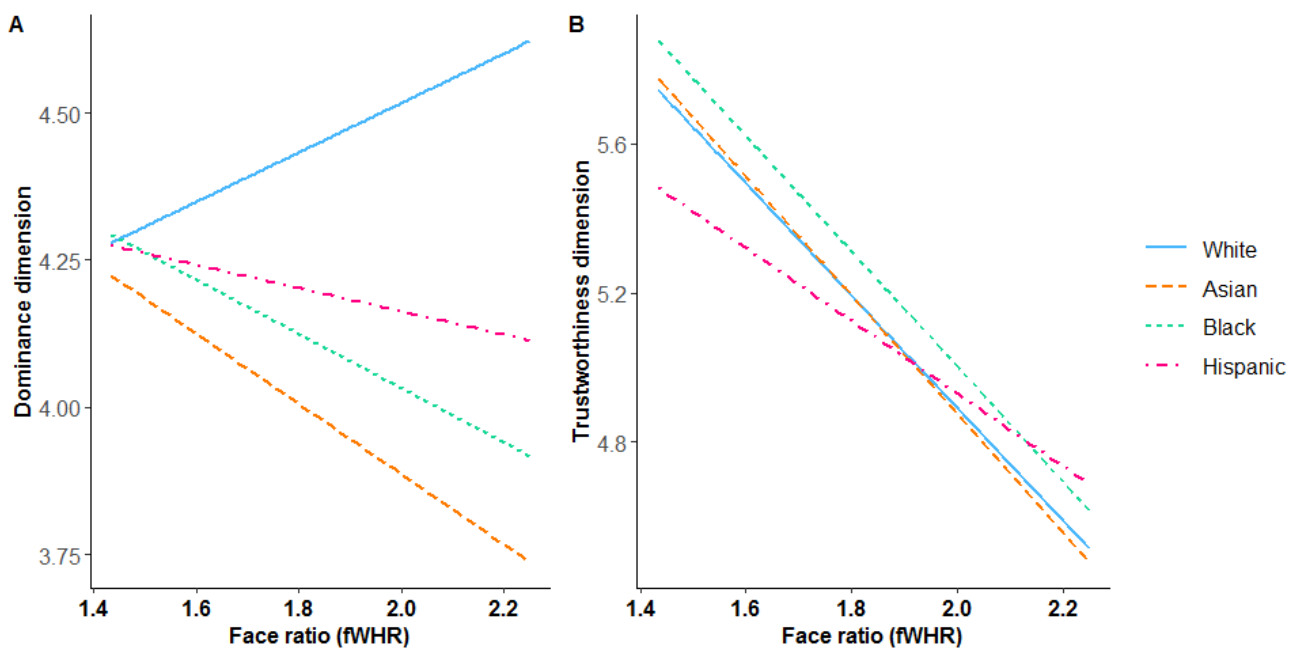

Figure 3. Moderation effects of the target's race. A) Race-by-fWHR on perceived dominance. B). Race-by-fWHR on perceived trustworthiness. 


\section{Exploratory analysis: moderation effect of pathogen prevalence}

I tested for the modulating influence of pathogen prevalence (a country level factor). To examine this, I ran similar mixed-effects models which included, in addition to direct effects of predictors, all 2-way interactions with study context (fWHR*gender, fWHR*age, fWHR*race, country-level pathogen score * fWHR) that separately predicting perceived dominance and perceived trustworthiness. In predicting perceived dominance, I found evidence for direct postive effect of pathogen prevelance (estimate $=0.28 \pm 0.07$ (SE), $\chi^{2}=$ $14.45, p<.001$ ), whereas the results indicated no support for the interaction term (pathogen prevelance $*$ face ratio: estimate $\left.=-0.06 \pm 0.03(\mathrm{SE}), \chi^{2}=3.50, p=.061\right)$. In the analysis of trustworthiness as an outcome variable, results showed no support for the direct influence of pathogen score (estimate $\left.=0.03 \pm 0.05(\mathrm{SE}), \chi^{2}=0.58, p=.448\right)$, whereas the interaction between country-level pathogen score and face ratio was significant (estimate $=0.28 \pm 0.02$ (SE), $\chi^{2}=167.02, p<.0001$ ). In interpreting the interaction effect (see Fig. 4B), I found that the negative relationship between face ratio and trustworthiness is less strong in countries with higher pathogen prevalence.
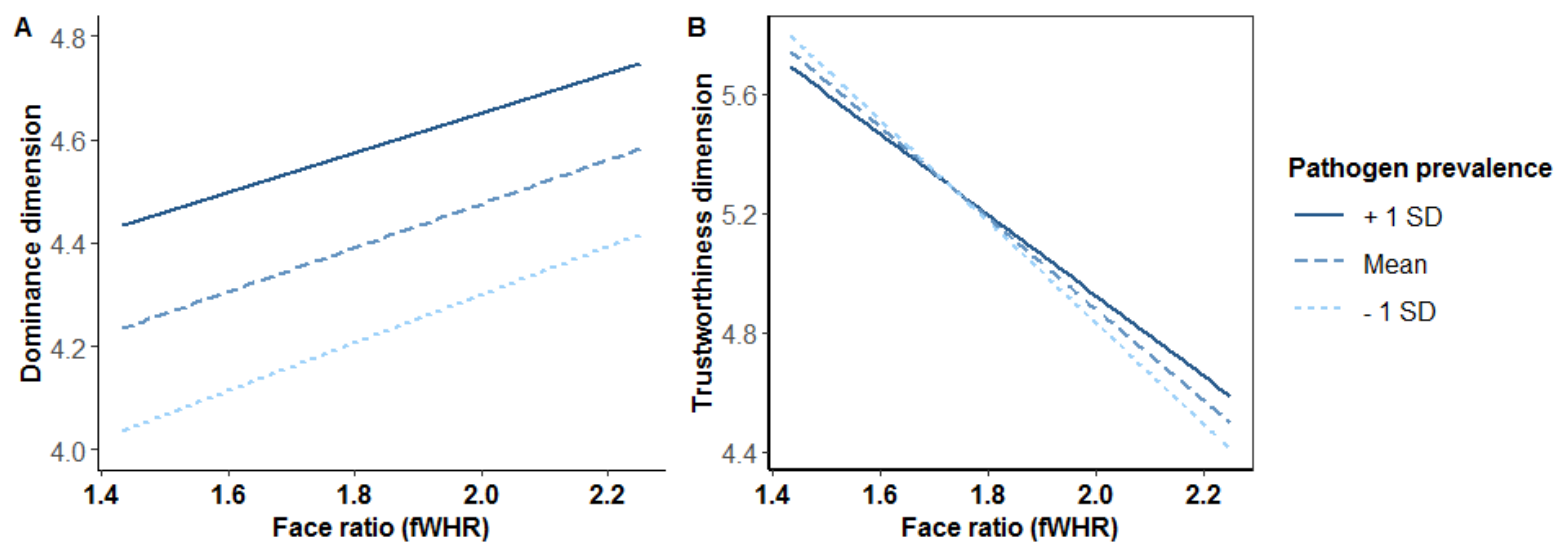

Figure 4. Moderation effects of target's pathogen prevalence. A) Country-level pathogen score-by-fWHR on perceived dominance. B). Country-level pathogen score-by-fWHR on perceived trustworthiness.

\section{Discussion}

People form appearance-based impressions rapidly, and these deductions are shown to have considerable social and economic consequences. In the present investigation, I revisit earlier reported relationships between face ratio and perceived dominance and trustworthiness, and study how the relationship varies by gender and race. Face-based trait impressions are theorized to be based on human adaptations to cues of threat or sexual selection. Therefore, these relationships are assumed to be universal across cultures and geographies, but are rarely tested with large cross-nation samples. Additionally, much of the previous research has been conducted with participants predominantly from WEIRD (Western, educated, industrialized, 
rich, and democratic) cultures. The current findings based on the data collected across eleven world regions corroborate the findings that view that gender plays a vital role in forming an appearance-based impression (Oh et al., 2020; Sutherland et al., 2015). More importantly, in the current work, I extend the existing literature by considering the moderating influence of race and environmental pathogen prevalence on the relationship between face ratio and trait judgments. In summary, the current work contributes to social perception research by further delineating how trait impressions based on the facial features are shaped by social categories (gender and race) and environmental factors (pathogen prevalence). 


\section{Data Accessibility Statement}

The data for the analysis conducted in the current manuscript were downloaded from two sources.

- Psychological Science Accelerator-001 project page on the OSF: (insert-URL-whendata-is-made-publicly-available)

- Chicago Face Database: https://chicagofaces.org/

\section{Acknowledgments}

Subramanya Prasad Chandrashekar would like to thank the Institute of International Business and Governance (IIBG), established with the substantial support of a grant from the Research Grants Council of the Hong Kong Special Administrative Region, China (UGC/IDS 16/17), for its support.

\section{Competing Interests}

The author has no competing interests to declare. 


\section{References}

Allport, G. W. (1954). The nature of prejudice. Cambridge, MA: Addison-Wesley.

Bates, D., Mächler, M., Bolker, B., \& Walker, S. (2015)Fitting Linear Mixed-Effects Models Using lme4. J. Stat. Softw. 67, 1-48.

Boshyan, J., Zebrowitz, L. A., Franklin Jr, R. G., McCormick, C. M., \& Carré, J. M. (2014). Age similarities in recognizing threat from faces and diagnostic cues. Journals of Gerontology Series B: Psychological Sciences and Social Sciences, 69(5), 710-718.

Carré, J. M., McCormick, C. M., \& Mondloch, C. J. (2009). Facial structure is a reliable cue of aggressive behavior. Psychological Science, 20(10), 1194-1198.

Carré, J. M., Morrissey, M. D., Mondloch, C. J., \& McCormick, C. M. (2010). Estimating aggression from emotionally neutral faces: Which facial cues are diagnostic?. Perception, 39(3), 356-377.

DeBruine, L. M., Jones, B. C., Crawford, J. R., Welling, L. L., \& Little, A. C. (2010). The health of a nation predicts their mate preferences: cross-cultural variation in women's preferences for masculinized male faces. Proceedings of the Royal Society B: Biological Sciences, 277(1692), 2405-2410.

DeBruine, L. M., Little, A. C., \& Jones, B. C. (2012). Extending parasite-stress theory to variation in human mate preferences. Behavioral and Brain Sciences, 35(2), 86-87.

Fiske, S. T. (2012). Managing ambivalent prejudices: Smart-but-cold and warm-but-dumb stereotypes. The Annals of the American Academy of Political and Social Science, $639,33-48$.

Fiske, S. T., Cuddy, A. J., Glick, P., \& Xu, J. (2002). A model of (often mixed) stereotype content: competence and warmth respectively follow from perceived status and competition. Journal of personality and social psychology, 82(6), 878.

Geniole, S. N., Denson, T. F., Dixson, B. J., Carré, J. M., \& McCormick, C. M. (2015). Evidence from meta-analyses of the facial width-to-height ratio as an evolved cue of threat. PloS one, 10(7).

Geniole, S. N., Keyes, A. E., Mondloch, C. J., Carré, J. M., \& McCormick, C. M. (2012). Facing aggression: Cues differ for female versus male faces. PLOS one, 7(1).

Geniole, S. N., Molnar, D. S., Carré, J. M., \& McCormick, C. M. (2014). The facial width-toheight ratio shares stronger links with judgments of aggression than with judgments of trustworthiness. Journal of Experimental Psychology: Human Perception and Performance, 40(4), 1526.

Gomulya, D., Wong, E. M., Ormiston, M. E., \& Boeker, W. (2017). The role of facial appearance on CEO selection after firm misconduct. Journal of Applied Psychology, 102(4), 617.

Haselhuhn, M. P., Wong, E. M., \& Ormiston, M. E. (2013). Self-fulfilling prophecies as a link between men's facial width-to-height ratio and behavior. PloS one, 8(8).

Hehman, E., Leitner, J. B., Deegan, M. P., \& Gaertner, S. L. (2015). Picking teams: When dominant facial structure is preferred. Journal of Experimental Social Psychology, 59, 51-59.

Jones, B. C., DeBruine, L. M., Flake, J. K., Liuzza, M. T., Antfolk, J., Arinze, N. C., . . Coles, N. A. (2018). To which world regions does the valence-dominance model of social perception apply? (Registered Report Stage 2). PsyArXiv.

Lefevre, C. E., \& Lewis, G. J. (2014). Perceiving aggression from facial structure: Further evidence for a positive association with facial width-to-height ratio and masculinity, 
but not for moderation by self-reported dominance. European Journal of Personality, 28(6), 530-537.

Lieberz, K. A., Windmann, S., Geniole, S. N., McCormick, C. M., Mueller-Engelmann, M., Gruener, F., ... \& Steil, R. (2017). The facial width-to-height ratio determines interpersonal distance preferences in the observer. Aggressive behavior, 43(5), 460470.

Little, A. C., DeBruine, L. M., \& Jones, B. C. (2011). Exposure to visual cues of pathogen contagion changes preferences for masculinity and symmetry in opposite-sex faces. Proceedings of the Royal Society B: Biological Sciences, 278(1714), 20322039.

Ma, D. S., Correll, J., \& Wittenbrink, B. (2015). The Chicago face database: A free stimulus set of faces and norming data. Behavior research methods, 47(4), 1122-1135.

Mileva, V. R., Cowan, M. L., Cobey, K. D., Knowles, K. K., \& Little, A. C. (2014). In the face of dominance: Self-perceived and other-perceived dominance are positively associated with facial-width-to-height ratio in men. Personality and Individual Differences, 69, 115-118.

Murray, D. R., \& Schaller, M. (2010). Historical prevalence of infectious diseases within 230 geopolitical regions: A tool for investigating origins of culture. Journal of CrossCultural Psychology, 41, 99-108

Oh, D., Buck, E. A., \& Todorov, A. (2019). Revealing hidden gender biases in competence impressions of faces. Psychological science, 30(1), 65-79.

Oh, D., Dotsch, R., Porter, J., \& Todorov, A. (2020). Gender biases in impressions from faces: Empirical studies and computational models. Journal of Experimental Psychology: General, 149(2), 323.

Oh, D., Grant-Villegas, N., \& Todorov, A. (2019). The eye wants what the heart wants: Female face preferences track partner personality preferences. https://doi.org/10.31234/osf.io/a7yed

Oosterhof, N. N., \& Todorov, A. (2008). The functional basis of face evaluation. Proceedings of the National Academy of Sciences, 105(32), 11087-11092.

Rezlescu, C., Duchaine, B., Olivola, C. Y., \& Chater, N. (2012). Unfakeable facial configurations affect strategic choices in trust games with or without information about past behavior. PloS one, 7(3).

Rosenberg, S., Nelson, C., \& Vivekananthan, P. S. (1968). A multidimensional approach to the structure of personality impressions. Journal of personality and social psychology, 9(4), 283.

Short, L. A., Mondloch, C. J., McCormick, C. M., Carré, J. M., Ma, R., Fu, G., \& Lee, K. (2012). Detection of propensity for aggression based on facial structure irrespective of face race. Evolution and Human Behavior, 33, 121-129.

Stirrat, M., \& Perrett, D. I. (2010). Valid facial cues to cooperation and trust: Male facial width and trustworthiness. Psychological science, 21(3), 349-354.

Sutherland, C. A., Young, A. W., Mootz, C. A., \& Oldmeadow, J. A. (2015). Face gender and stereotypicality influence facial trait evaluation: Counter-stereotypical female faces are negatively evaluated. British Journal of Psychology, 106(2), 186-208.

Thornhill, R., \& Gangestad, S. W. (2006). Facial sexual dimorphism, developmental stability, and susceptibility to disease in men and women. Evolution and Human Behavior, 27(2), 131-144. 
Valentine, K. A., Li, N. P., Penke, L., \& Perrett, D. I. (2014). Judging a man by the width of his face: The role of facial ratios and dominance in mate choice at speed-dating events. Psychological science, 25(3), 806-811.

Willis, J., \& Todorov, A. (2006). First impressions: Making up your mind after a 100-ms exposure to a face. Psychological science, 17(7), 592-598.

Wilson, J. P., \& Rule, N. O. (2015). Facial trustworthiness predicts extreme criminalsentencing outcomes. Psychological science, 26(8), 1325-1331. 


\section{Supplementary Section}

\section{Detailed results}

Table S1. Direct effects of face ratio on perceived dominance

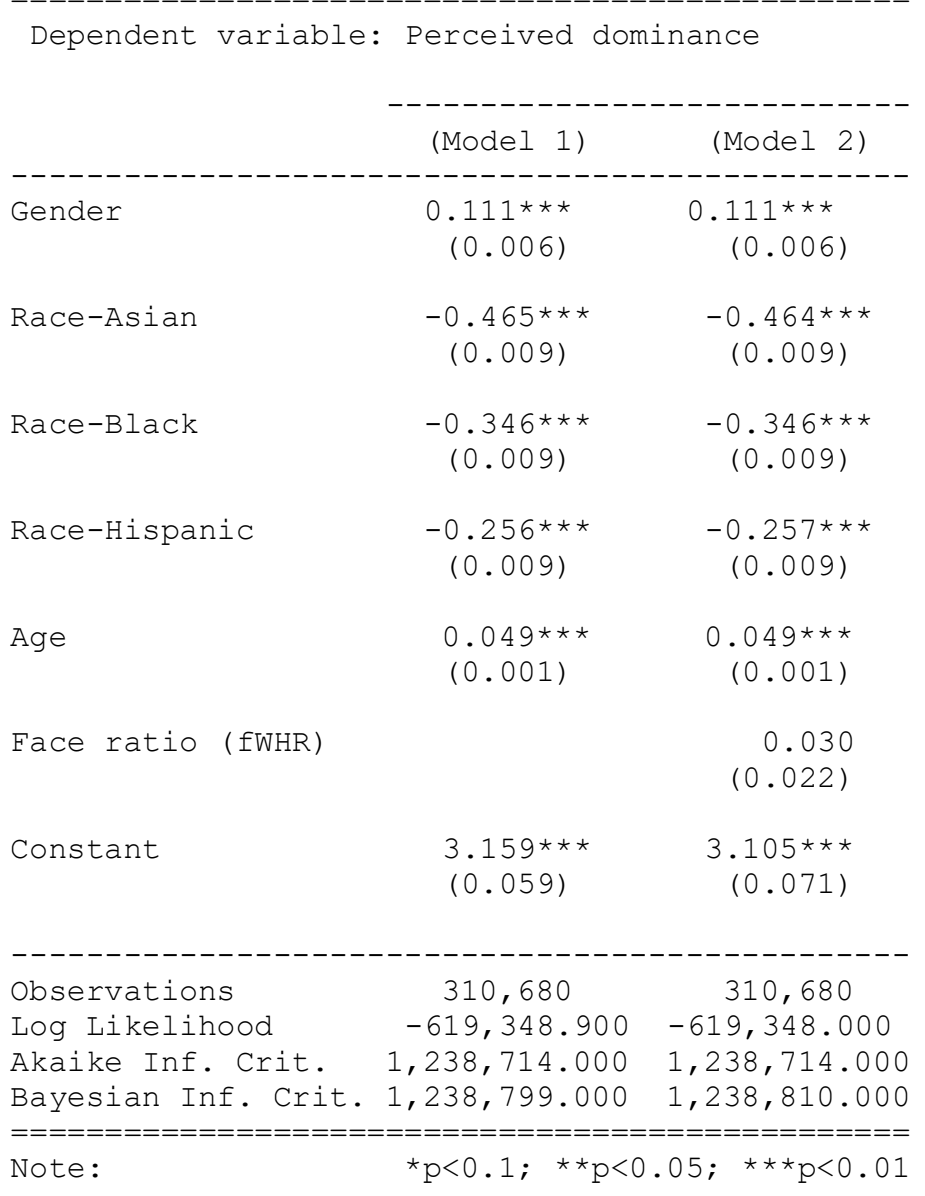


Table S2. Direct effects of face ratio on perceived trustworthiness

\begin{tabular}{|c|c|c|}
\hline Dependent variak & $\begin{array}{l}\text { le: Perceived tr } \\
-(\text { Model 1) }\end{array}$ & $\begin{array}{l}\text { rustworthiness } \\
\text { (Model 2) }\end{array}$ \\
\hline Gender & $\begin{array}{r}-0.273 * \star \star \\
(0.004)\end{array}$ & $\begin{array}{r}-0.269 * * \star \\
(0.004)\end{array}$ \\
\hline Race -Asian & $\begin{array}{r}0.038 * * * \\
(0.006)\end{array}$ & $\begin{array}{r}0.022 * * * \\
(0.006)\end{array}$ \\
\hline Race -Black & $\begin{array}{r}0.133 * * * \\
(0.006)\end{array}$ & $\begin{array}{r}0.127 * \star * \\
(0.006)\end{array}$ \\
\hline Race -Hispanic & $(0.006)^{-0.0}$ & $\begin{array}{l}044 * * * \\
(0.006)\end{array}$ \\
\hline Age & $\begin{array}{c}-0.011 * * * \\
(0.001)\end{array}$ & $\begin{array}{c}-0.010 * * * \\
(0.001)\end{array}$ \\
\hline Face ratio (fWHR) & & $\begin{array}{c}-0.831 * * * \\
(0.013)\end{array}$ \\
\hline Constant & $\begin{array}{l}5.423 * * * \\
(0.033)\end{array}$ & $\begin{array}{l}6.931 * * * \\
(0.041)\end{array}$ \\
\hline $\begin{array}{l}\text { Observations } \\
\text { Log Likelihood } \\
\text { Akaike Inf. Crit. } \\
\text { Bayesian Inf. Crit. }\end{array}$ & $\begin{array}{l}751,560 \\
-1,469,880.000 \\
2,939,777.000 \\
2,939,869.000\end{array}$ & $\begin{array}{l}751,560 \\
-1,467,941.000 \\
2,935,900.000 \\
2,936,004.000\end{array}$ \\
\hline
\end{tabular}


Table S3. Full interaction model (DV: Perceived dominance)

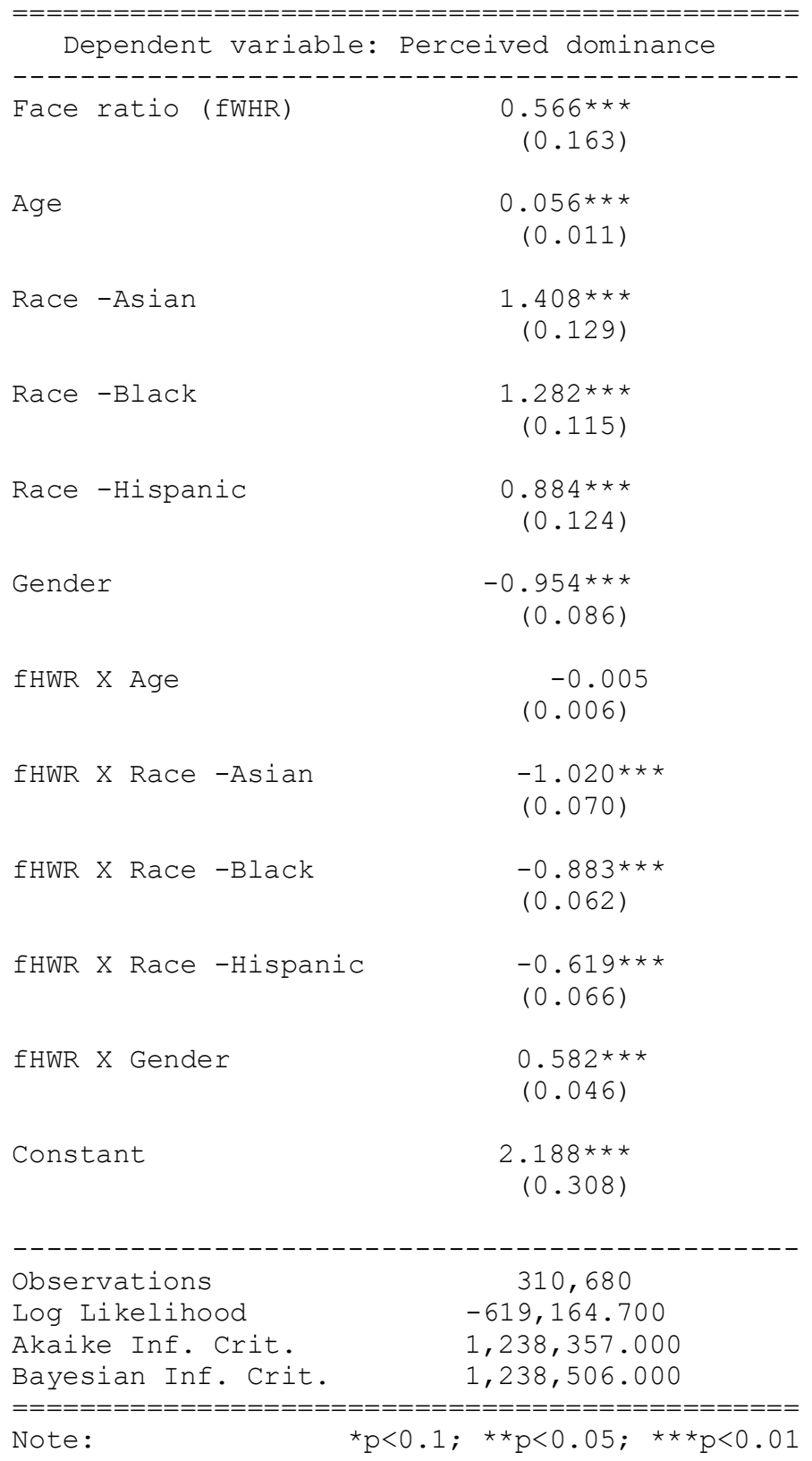


17

Figure S1. Plot of regression coefficients of full interaction (DV: Perceived dominance)

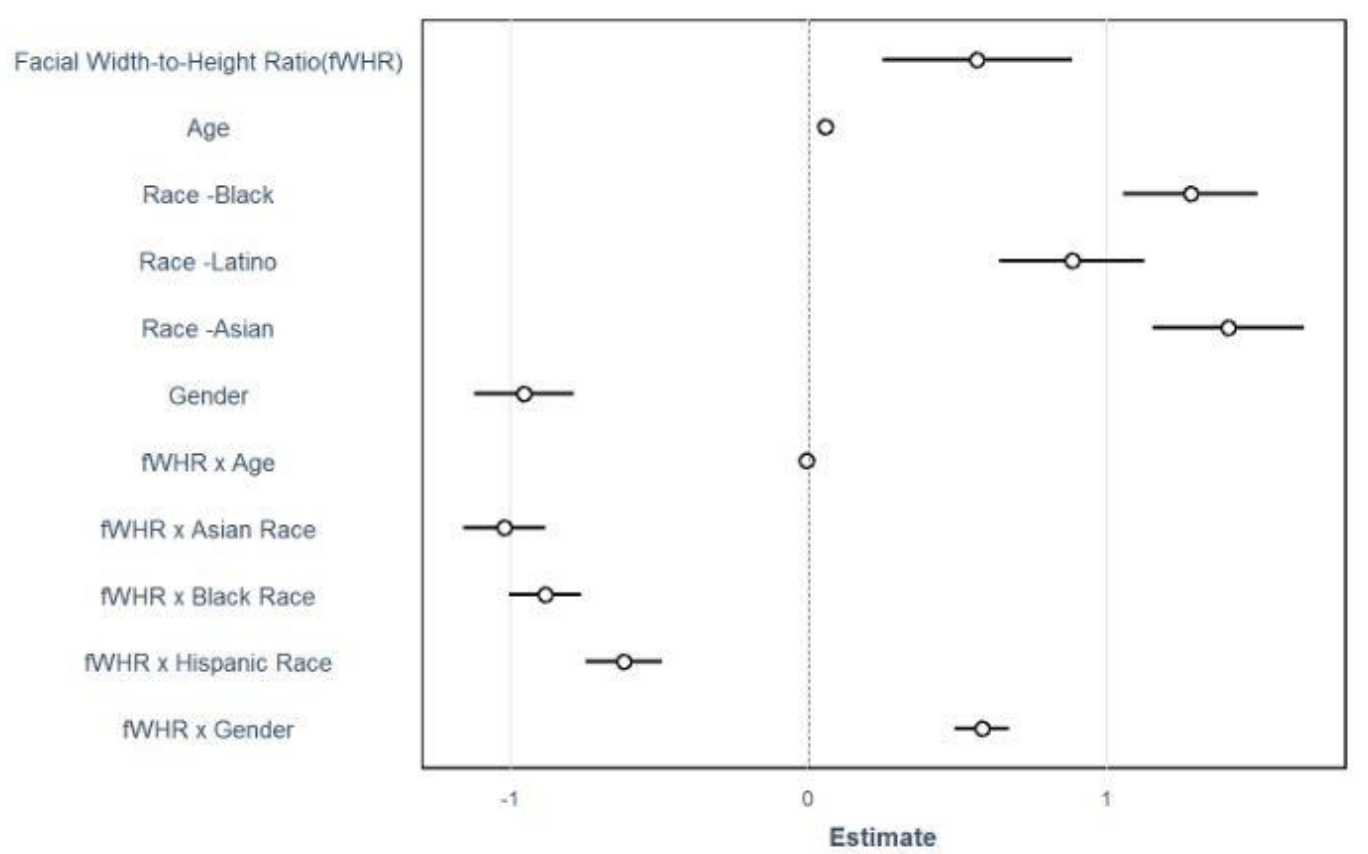


Table S4. Full interaction model (DV: Perceived trustworthiness)

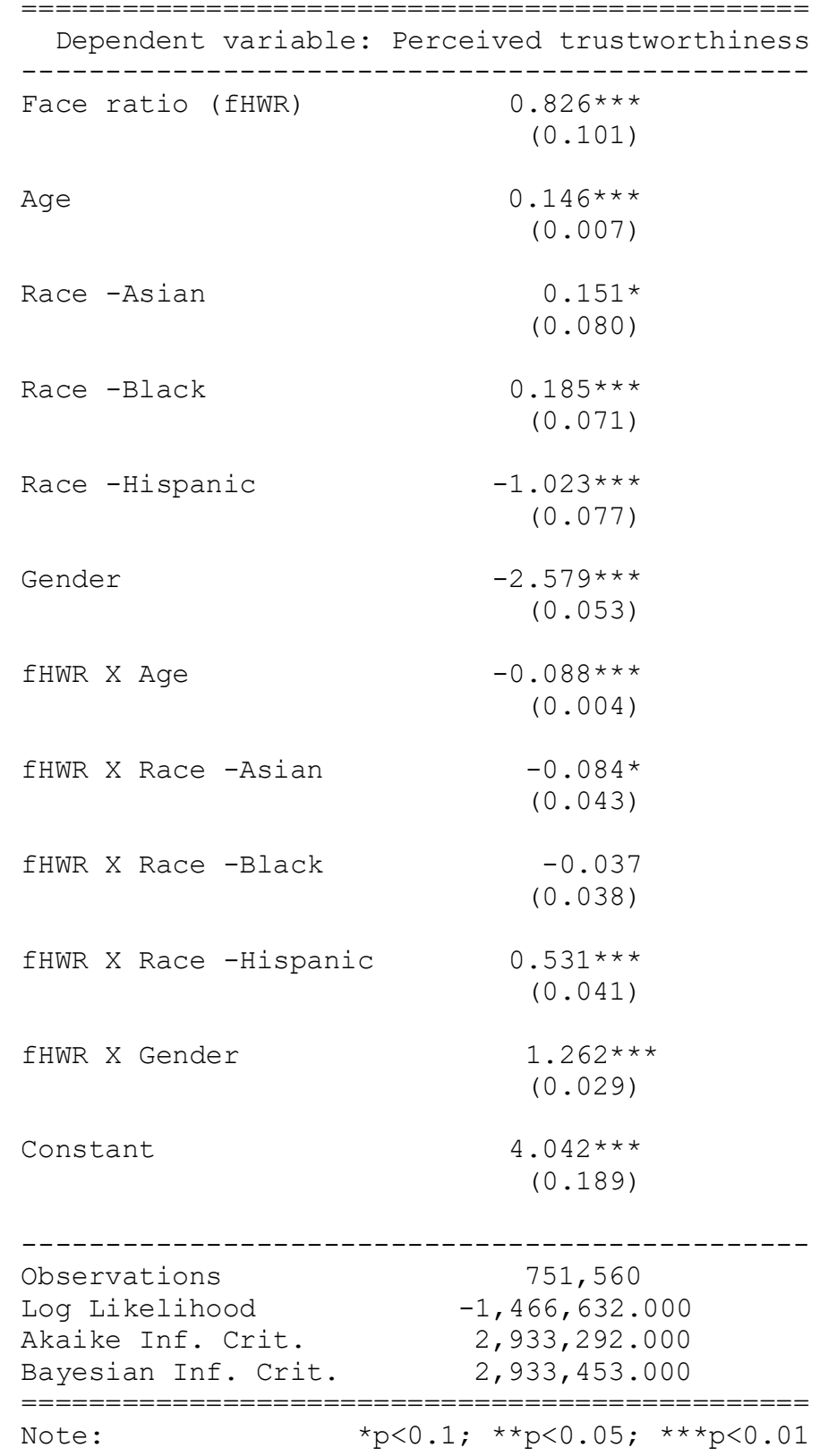


Figure S2. Plot of regression coefficients of full interaction model (DV: Perceived trustworthiness)

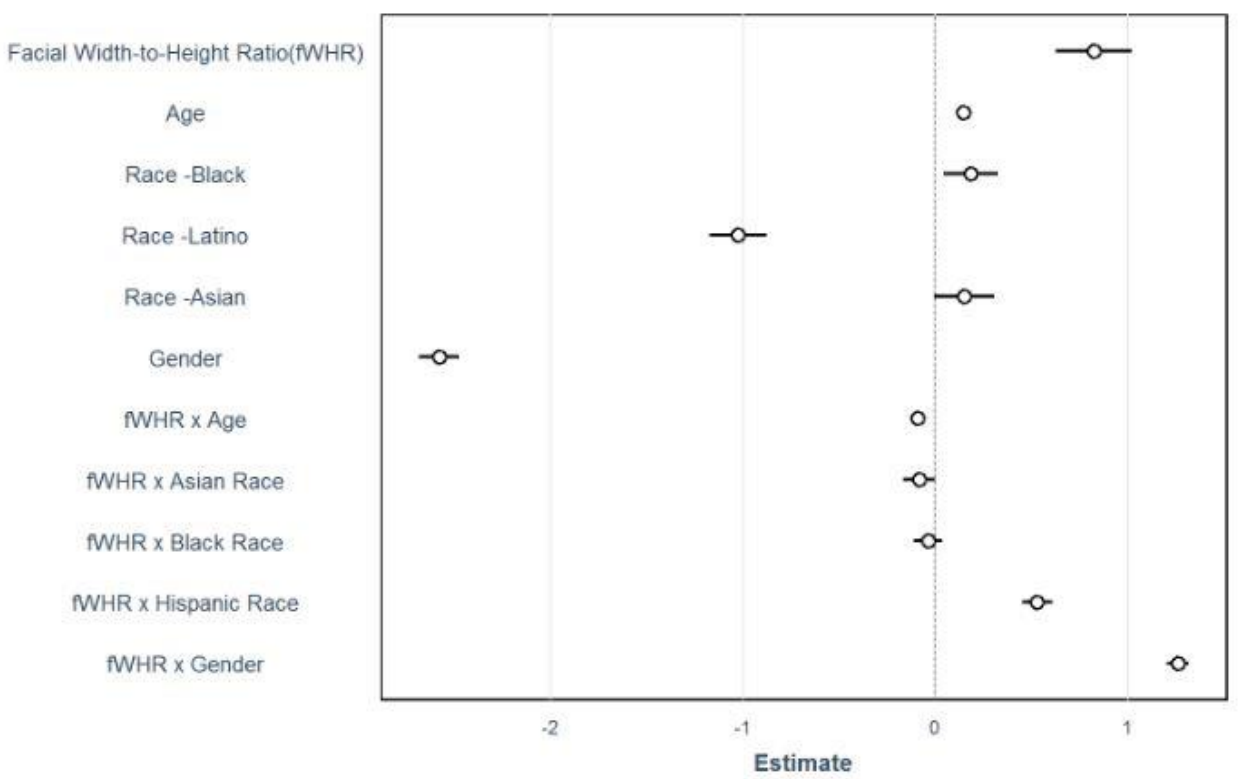


Table S5. Direct and interaction effects of Pathogen prevalence (DV: Perceived dominance)

Dependent variable: Perceived dominance

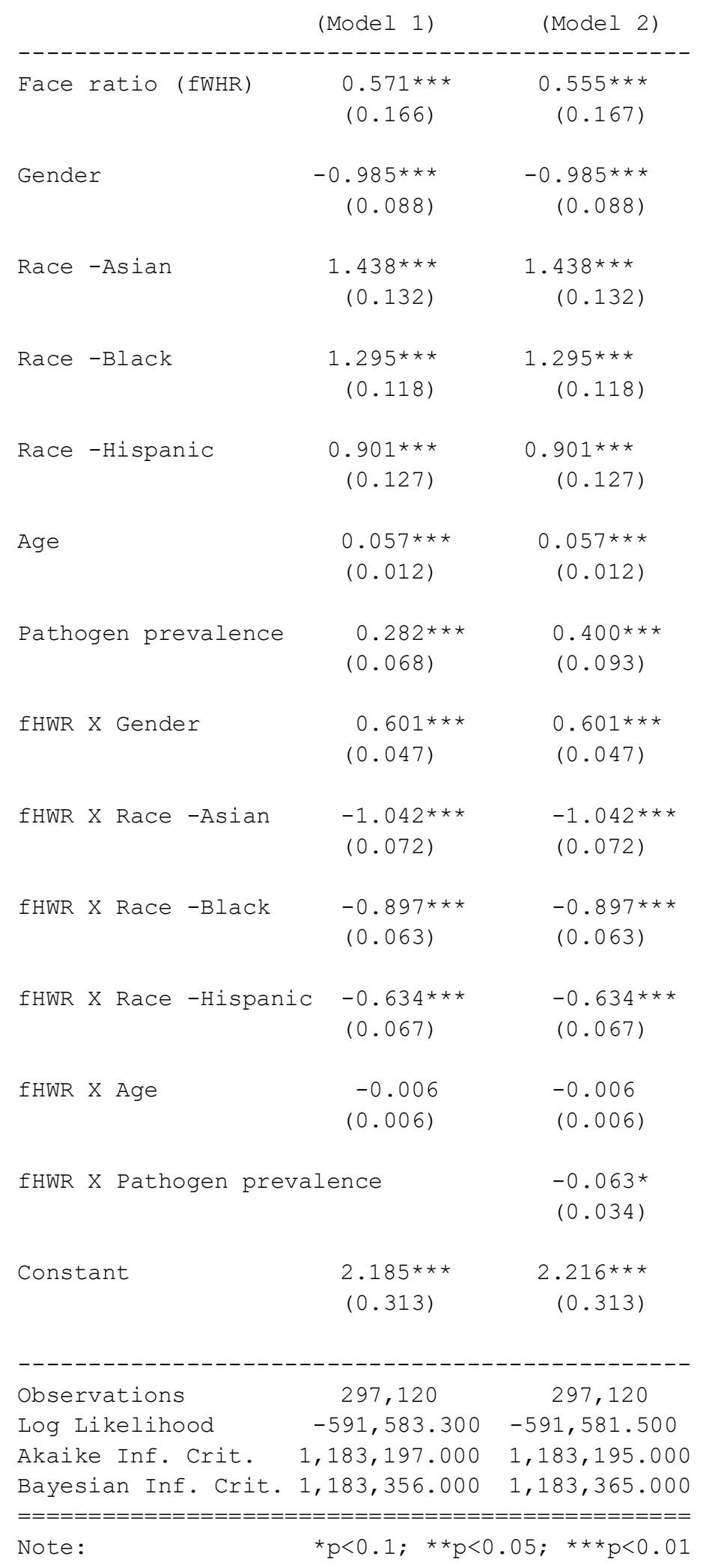


Table S6. Direct and interaction effects of Pathogen prevalence (DV: Perceived dominance)

\begin{tabular}{|c|c|c|}
\hline Dependent variable & $\begin{array}{l}\text { Perceived t } \\
\text { (Model 1) }\end{array}$ & $\begin{array}{l}\text { rustworthiness } \\
\text { (Model 2) }\end{array}$ \\
\hline Face ratio (fWHR) & $\begin{array}{l}0.839 * * \star \\
(0.102)\end{array}$ & $\begin{array}{l}0.916 * \star \star \\
(0.103)\end{array}$ \\
\hline Gender & $\begin{array}{r}-2.603 * \star \star \\
(0.054)\end{array}$ & $\begin{array}{r}-2.603 * \star \star \\
(0.054)\end{array}$ \\
\hline Race -Asian & $\begin{array}{l}0.147 * \\
(0.081)\end{array}$ & $\begin{array}{l}0.147 * \\
(0.081)\end{array}$ \\
\hline Race -Black & $\begin{array}{r}0.194 * * * \\
(0.072)\end{array}$ & $\begin{array}{r}0.194 * * * \\
(0.072)\end{array}$ \\
\hline Race -Hispanic & $\begin{array}{r}-1.033 * * * \\
(0.078)\end{array}$ & $\begin{array}{r}-1.033 * * * \\
(0.078)\end{array}$ \\
\hline Age & $\begin{array}{l}0.148 * * * \\
(0.007)\end{array}$ & $\begin{array}{l}0.148 * * * \\
(0.007)\end{array}$ \\
\hline Pathogen prevalence & $\begin{array}{c}0.035 \\
(0.046)\end{array}$ & $\begin{array}{c}-0.482 * * * \\
(0.061)\end{array}$ \\
\hline fHWR X Gender & $\begin{array}{l}1.273 * * * \\
(0.029)\end{array}$ & $\begin{array}{l}1.273 * * * \\
(0.029)\end{array}$ \\
\hline fHWR X Race -Asian & $\begin{array}{l}-0.081^{\star} \\
(0.044)\end{array}$ & $\begin{array}{l}-0.081^{\star} \\
(0.044)\end{array}$ \\
\hline fHWR X Race -Black & $\begin{array}{l}-0.037 \\
(0.039)\end{array}$ & $\begin{array}{l}-0.037 \\
(0.039)\end{array}$ \\
\hline fHWR X Race -Hispanic & $\begin{aligned}= & 0.537 * * * \\
& (0.041)\end{aligned}$ & $\begin{array}{l}0.537 * * \star \\
(0.041)\end{array}$ \\
\hline fHWR X Age & $\begin{array}{c}-0.090 * * * \\
(0.004)\end{array}$ & $\begin{array}{c}-0.090 * * * \\
(0.004)\end{array}$ \\
\hline fHWR X Pathogen preva & alence & $\begin{array}{l}0.278 * * * \\
(0.022)\end{array}$ \\
\hline Constant & $\begin{array}{l}4.024 * * * \\
(0.193)\end{array}$ & $\begin{array}{l}3.881 * * * \\
(0.193)\end{array}$ \\
\hline $\begin{array}{l}\text { Observations } \\
\text { Log Likelihood } \\
\text { Akaike Inf. Crit. } \\
\text { Bayesian Inf. Crit. } 2\end{array}$ & $\begin{aligned} & 727,320 \\
&-1,420,509.000 \\
& 2,841,048.000 \\
& 2,841,220.000\end{aligned}$ & $\begin{array}{c}727,320 \\
-1,420,425.000 \\
2,840,883.000 \\
2,841,067.000\end{array}$ \\
\hline
\end{tabular}

